\title{
Internalized Stigma of Mental Illness in Swedish Patients with Mental Illness
}

\author{
Lars Jacobsson ${ }^{1 *}$, Magnus Lejon ${ }^{1}$, Anette Edin-Liljegren ${ }^{2 *}$ \\ ${ }^{1}$ Department of Clinical Sciences, Psychiatry, Umeå University, Umeå, Sweden \\ ${ }^{2}$ Center for Rural Medicin, Storuman, Sweden \\ Email: ${ }^{\star}$ lars.jacobsson@umu.se, *anette.edin-liljegren@umu.se
}

How to cite this paper: Jacobsson, L., Lejon, M. and Edin-Liljegren, A. (2017) Internalized Stigma of Mental Illness in Swedish Patients with Mental Illness. Open Journal of Psychiatry, 7, 123-130. https://doi.org/10.4236/ojpsych.2017.73012

Received: March 27, 2017

Accepted: June 30, 2017

Published: July 3, 2017

Copyright (c) 2017 by authors and Scientific Research Publishing Inc. This work is licensed under the Creative Commons Attribution International License (CC BY 4.0).

http://creativecommons.org/licenses/by/4.0/

cc) (†) Open Access

\begin{abstract}
Stigma and discrimination because of epilepsy, leprosy and HIV/aids has decreased over the years, but this has not happened as regards mental illness. One aspect of the stigma issue is what has been described as self-stigmatization, the way the mentally ill look at themselves. The aim of this study was to illuminate the self-perception of mentally ill persons in a Swedish setting. An internationally well established questionnaire, Internalized Stigma of Mental Illness scale (ISMI) was used to investigate two samples of out-patients from northern Sweden $(\mathrm{N}=260)$. Fifty two percent reported "minimum stigma", $35 \%$ "mild" and 13\% "moderate/severe" stigma. As many as 58\% agreed to the statement "I am embarrassed or ashamed that I have a mental illness". The levels of internalized stigma are rather high, but somewhat lower than reported from some other European and an Iranian study using the same methodology. In spite of several campaigns aimed at reducing the stigma and discrimination because of mental illness in Sweden, still the experience of self stigma is rather high. There is an urgent need to further developed anti-stigma strategies.
\end{abstract}

\section{Keywords}

Internalized Stigma, Perceived Discrimination, Mental Disorders, Sweden

\section{Introduction}

Stigma and discrimination because of epilepsy, intellectual disabilities, neurological disorders, cancer and even HIV/aids has decreased over the years, especially in high-income countries. There are several possible reasons for this. Probably the most important is a more successful treatment of these disorders and an increasing educational level in the general population. Also common knowledge about causes and treatments has increased. However, stigma and 
discrimination because of mental illness is still a pressing issue in spite of a number of initiatives taken to reduce the problem. As regards mental disorders our explanatory models are not sufficiently developed and we still lack effective treatments. The consequences for individuals suffering and their families and society at large are great. One is a negative effect on the development of mental health services and research funding another is a reluctance to seek professional help from individuals suffering from mental problems.

As regards the study of stigma and discrimination there have been two main approaches over the years. One is to look at the public perception of mental disorders and there are now numerous studies from different parts of the world looking at this aspect of the problem, all showing very negative attitudes and behaviour towards mentally ill and also psychiatric services. In Sweden there are a few studies on public perceptions and attitudes towards mental illness and mentally ill persons [1] [2] [3] [4]. In one study on attitudes towards mental illness and psychiatric treatment the same questions were used to measure attitudes in the same population in 1976, 2003 and 2014 [1]. The attitudes towards people with mental illness have not generally become more positive over the years. In 2014 almost a quarter of the population still think that "people with mental illness commit violent acts more than others". In 2014 even more people than in 1976 agreed to the statement that "mental illness harms the reputation more than a physical disease (77.2\% versus $52.8 \%$ ).

Another approach which has become increasingly focused the last decades, is the self perception of persons suffering from mental disorders. The way they themselves look at mental disorders and the way they look at themselves as having mental problems are considered an important part of the problem. This has been described as self-stigmatization or internalized stigma. Internalized stigma has been defined as "the devaluation, shame, secrecy and withdrawal triggered by appling negative stereotypes to oneself [5].

Ritscher and co-workers have developed a questionnaire, "The Internalized Stigma of Mental Illness scale (ISMI) [5]. It has now been used in a great number of countries all over the world. ISMI has been comprehensively evaluated recently by Boyd et al. and they conclude that ISMI "has sound psychometric properties across a variety of languages, cultures, conditions and situations" [6]. They found 81 works from all over the world in their search for published research papers that had used ISMI during the period 2002-2013.

The aim of this study was to illuminate the self perception of mentally ill persons in a Swedish setting and compare this with similar studies using ISMI from other socio-cultural contexts. One objective was also to compare internalized stigma in a very sparsely populated area and an urban area in Sweden.

\section{Methods}

The study was conducted in two sites in Västerbotten's county in northern Sweden in 2013. One sample was recruited from the outpatient department of the psychiatric clinic at the University hospital in Umea $(\mathrm{N}=188)$. Umea is a uni- 
versity town in northern Sweden and the catchment area of the clinic has a population of 120,000 inhabitants. Another sample was collected from an outpatient unit in the rural, very sparsely populated area of the Lapland part of the county $(\mathrm{N}=72)$. The two populations were convenience samples of persons attending the two units with a mix of diagnoses over the whole spectrum of mental disorders.

Internalized Stigma of Mental Illness scale is a 29 item questionnaire grouped into five basically theory driven subscales; Alienation, Stereotype endorsement, Perceived discrimination, Social withdrawal and Stigma resistance. In their study of 47 versions of ISMI Boyd et al. showed good psychometric properties including reliability, test re-test reliability, internal consistency reliability and also a number of validity studies [6]. The questionnaire was translated into Swedish and back-translated.

The project was approved by the Regional research ethics committee (dnr 09-094M) and conducted according to the principles of the Helsinki declaration. Participation was voluntary and anonymous.

Statistical analyses were performed with the SPSS package version 22 to calculate per cents agreeing to the questions, means and standard deviations of the subscales and total scale, Cronbach Alpha for the subscales and total scale and stigma levels according to the method developed by Lysaker et al. [7]. They proposed that a score of 2 or less should be labelled "minimal stigma", scores between 2 and 2.5 could be labelled "mild stigma", scores 2.5 to 3 "moderate stigma" and scores greater than 3 labelled "severe stigma". In the table are also results from some other European and an Iranian study shown [8] [9] [10]. An exploratory factor analysis of the 29 questions was also performed.

\section{Results}

In Table 1 are some socio-demographic data presented. The two populations differ as regards educational level and age distribution. The rural cohort is older and has a lower educational level which is consistent with the known differences between rural and urban areas in Sweden.

In Table 2 are presented the responses to the individual items as well as the composition of the different subscales.

With respect to the items in the Alienation subscale more than half of the respondents agreed to four of the six items, for example "Having a mental illness has spoiled my life" (54\% "agree" or "strongly agree"). As regards the "Stereotype endorsement" scale the responses were less stigmatizing but still $25 \%$ agreed to the statement "People with mental illness cannot live a good, rewarding life". As regards "Discrimination experience" about 20\% agreed to all items e.g. "People ignore me or take me less seriously because I have a mental illness" (20\%). Even the items in the "Social withdrawal" scale get high levels of approval e.g. "I don't socialize as much as I used to because my mental illness might make me look or be have weird" (34\%). On the other hand quite many indicated high levels of stigma resistance e.g. $60 \%$ agreed to the statement "I can have a good 
fulfilling life despite my mental illness".

In Table 3 are presented the means of the different subscales and standard deviations and also levels of stigma according to Lysaker et al. [7]. It is noteworthy that the highest levels of experienced stigma are in the Alienation and Social withdrawal scales.

Cronbach Alpha for the subscales was satisfactory differing between 0.707 and 0.801 except for the stigma resistance scale (0.581). Cronbach alpha for the total scale was 0.860 .

The factor analysis gave seven factors with eigenvalues bigger than 1 . Seven factors explain $60 \%$ of the variance in the 29 variables. Five factors explain $53 \%$ of the variance in the 29 variables. There was a reasonable good concordance with the five subscales proposed by the constructors of ISMI. There were no significant differences between the urban and the rural populations as regards the means of the subscales and also levels of stigma according to Lysaker et al.

\section{Discussion}

There are some limitations of this study. One is the representativity of the samples. In both subsamples there is a mix of diagnosis, depression being the major part (53\% affective disorders) followed by anxiety disorders, but there were also patients with a psychotic disorder, however under control. The most severe cases were excluded as all were out-patients. We think, however, that the sample is rather representative for the general population of patients attending a specialist psychiatric clinic.

ISMI is one of the most commonly used methods to measure internalized stigma and the mere fact that it has been so widely used by researchers in the

Table 1. Socio-demographic data Sweden $(\mathrm{N}=263)$.

\begin{tabular}{ccc}
\hline Characteristic & $\%$ & $\mathbf{N}$ \\
\hline Gender & 32 & 84 \\
Male & 67 & 176 \\
Female & 1 & 3 \\
Missing & & \\
Education & 59 & 154 \\
$<12$ years & 37 & 97 \\
$\geq 12$ years & 4 & 12 \\
Missing & & \\
Age & & 69 \\
18 - 25 years & 26 & 102 \\
26 - 40 years & 39 & 80 \\
41 - 64 years & 30 & 8 \\
$>65$ years & 3 & 4 \\
Missing & 2 & 83 \\
\hline & & 8 \\
\hline
\end{tabular}


Table 2. Responses to internalized stigma of mental illness items in percent $(\mathrm{N}=263)$.

\begin{tabular}{|c|c|c|c|c|c|}
\hline & & $\begin{array}{l}\text { Strongly } \\
\text { disagree }\end{array}$ & Disagree & Agree & $\begin{array}{c}\text { Strongly } \\
\text { agree }\end{array}$ \\
\hline Item nr & Alienation & & & & \\
\hline 1 & I feel out of place in the world because I have mental illness & 23 & 41 & 27 & 9 \\
\hline 17 & Having a mental illness has spoiled my life & 19 & 27 & 32 & 22 \\
\hline 21 & People without mental illness could not possibly understand me & 15 & 28 & 36 & 22 \\
\hline 5 & I am embarrassed or ashamed that I have a mental illness & 19 & 23 & 33 & 25 \\
\hline 16 & I am disappointed in myself for having a mental illness & 22 & 20 & 29 & 30 \\
\hline \multirow[t]{2}{*}{8} & I feel interior to others who don't have mental illness & 26 & 29 & 31 & 14 \\
\hline & Stereotype endorsement & & & & \\
\hline 29 & Stereotypes about the mental ill apply to me & 58 & 29 & 10 & 3 \\
\hline 18 & People can tell that I have a mental illness by the way I look & 59 & 25 & 11 & 5 \\
\hline 2 & Mentally ill people tend to be violent & 42 & 42 & 13 & 4 \\
\hline 19 & Because I have a mental illness, I need others to make most decisions for me & 68 & 23 & 7 & 3 \\
\hline 10 & People with mental illness cannot live a good, rewarding life & 43 & 32 & 17 & 8 \\
\hline 6 & Mentally ill people should not get married & 87 & 8 & 3 & 2 \\
\hline \multirow[t]{2}{*}{23} & I can't contribute anything to society because I have a mental illness & 59 & 21 & 13 & 7 \\
\hline & Discrimination experience & & & & \\
\hline 3 & People discriminate against me because I have mental illness & 51 & 32 & 16 & 2 \\
\hline 28 & Others think that I can't achieve much in life because I have a mental illness & 46 & 31 & 16 & 6 \\
\hline 22 & People ignore me or take me less seriously just because I have a mental illness & 47 & 33 & 13 & 7 \\
\hline 15 & People often patronize me, or treat me like a child, just because I have a mental illness & 49 & 31 & 12 & 7 \\
\hline \multirow[t]{2}{*}{25} & Nobody would be interested in getting close to me because I have a mental illness & 48 & 32 & 13 & 6 \\
\hline & Social withdrawal & & & & \\
\hline 11 & I don't talk about myself much because I don't want to burden others with my mental illness & 18 & 28 & 29 & 25 \\
\hline 9 & $\begin{array}{l}\text { I don't socialize as much as I used to because my mental illness might make me look or behave } \\
\text { "weird" }\end{array}$ & 36 & 30 & 22 & 12 \\
\hline 12 & Negative stereotypes about mental illness keep me isolated from the "normal" world & 31 & 36 & 23 & 9 \\
\hline 20 & I stay away from social situations in order to protect my family or friends from embarrassment & 60 & 25 & 10 & 5 \\
\hline 13 & Being around people who don't have a mental illness makes me feel out of place or inadequate & 34 & 31 & 26 & 9 \\
\hline \multirow[t]{2}{*}{4} & I avoid getting close to people who don't have a mental illness to avoid rejection & 60 & 25 & 12 & 3 \\
\hline & Stigma resistance & & & & \\
\hline 14 & A feel comfortable being seen in public with an obviously mentally ill person & 18 & 22 & 34 & 26 \\
\hline 26 & In general, I am able to live my life the way I want to & 27 & 30 & 26 & 17 \\
\hline 27 & I can have a good fulfilling life, despite my mental illness & 14 & 26 & 35 & 25 \\
\hline 7 & People with mental illness make important contributions to society & 5 & 5 & 22 & 69 \\
\hline 24 & Living with mental illness has made me a tough survivor & 18 & 26 & 33 & 24 \\
\hline
\end{tabular}


Table 3. Subscale means and stigma levels according to Lysaker in percent.

\begin{tabular}{ccccc}
\hline ISMI subscale means & Sweden (SD) & Europe (schiz) & Europe (affect) $^{* *}$ & Iran $^{* * *}$ \\
\hline Alienation & $2.51(0.72)$ & 2.53 & 2.22 & 2.33 \\
Stereotype endorsement & $1.60(0.49)$ & 2.19 & 1.59 & 2.30 \\
Discrimination & $1.77(0.69)$ & 2.43 & 1.91 & 2.32 \\
Social withdrawal & $2.01(0.66)$ & 2.48 & 1.98 & 2.64 \\
Stigma resistance & $2.78(0.60$ & 2.47 & 2.81 & 2.46 \\
Level of stigma & & & & \\
Minimum $(<2)$ & 52 & 23 & 45.6 & 40 \\
Mild $(2-2.49)$ & 35 & 34 & 30.8 & 21 \\
Moderate $(2.5-3)$ & 10 & 29.4 & 18.1 & 27 \\
Severe $(>3)$ & 3 & 12.5 & 3.6 & 12 \\
\hline
\end{tabular}

*Brohan et al., 2010 (schiz); ${ }^{* * B r o h a n ~ e t ~ a l ., ~} 2011$ (affect); ${ }^{* * *}$ Ghanean et al., 2011.

field indicates that it has at least a good face validity. It is also apparent that in the many different studies there has been a gradient in that higher levels of internalized stigma are associated with symptom severity as is shown in Table 3 with the schizophrenia group showing the highest level of internalized stigma. ISMI has also been adapted for studying other disorders as eating disorders, epilepsy, inflammatory bowel disease, leprosy, smoking and also parents and caregivers of people with mental illness [6]. It is also reported from a number of groups using ISMI that it has been rather easy to translate and that the items have been easily understood and perceived meaningful for the patients, which also adds to the validity of the instrument. All this indicates that ISMI is a useful and meaningful tool.

As regards the level of stigma it is difficult to be decisive about what is a high or low level of stigma, but we think that the Lysaker et al. scale is of interest. When comparing other studies as shown in Table 3 our Swedish samples seem to have a lower level of stigma compared to the two European samples and especially as compared to the Iranian sample. This might be an effect of the different diagnostic groups included in the study as regards the European samples. Our impression is that the Iranian and Swedish samples are rather equal as regards composition being a mix of different common outpatient cases. The schizophrenia sample from Europe shows the highest level of stigma and the European affective group seems closer to the Swedish sample as regards level of stigma.

Compared to the Iranian sample it is interesting to see that the Swedish group more often endorse items belonging to the alienation subscale as item 5 "I am embarrassed or ashamed that I have a mental illness" and item 16 "I am disappointed in myself for having a mental illness". This might be a consequence of the individualistic kind of society Sweden represents. In Iran it is a common view that what happens to you might be the will of God or other external forces that influence your life. Whilst in Sweden the individuals are considered responsible for what happens to him/her. 
Our Swedish samples as well as other European samples seem to have a lower level of internalized stigma than many other international samples, but still more than half of the patients indicate mild or higher levels of stigma. This fact makes it still important to continue working on how stigma can be resisted and reduced. It is disappointing that the Swedish population in spite of been exposed to several national efforts to reduce stigma and discrimination of mentally ill persons still has negative and discriminating attitudes towards mentally ill persons [11].

As regards how to reduce stigma and discrimination in general and internalized stigma there has been a variety of campaigns aiming at informing the general public about the nature of mental disorders and possibilities of treatment [11] [12]. The effect of this kind of campaigns is not impressive but reasonably they will contribute to a change in the long-term. Probably the most important would be to develop our knowledge about the causes of different mental disorders and more rational, focused and effective treatments. The problem of funding of mental health research must be highlighted. In Sweden for example cancer research is getting ten times more money than psychiatric care research in spite of the fact that mental illness is the most common cause of sick leave and also an important part of the suicide problem, which causes 1500 lives per year in Sweden. As regards internalized stigma there are now some more focused projects like the "Acceptance and commitment therapy" and also Cognitive-behavioural therapy based interventions developed targeting reduction of internalized stigma [13] [14]. As regards development of services the availability of services is important. To use internet approaches would be another very useful way of making psychotherapeutic approaches available, especially to the younger generations.

\section{Conclusion}

The highest levels of experienced stigma were found as regards items in the Alienation scale followed by items in the Social withdrawal scale. Items in the "Stereotype endorsement" scale and "Discrimination experience" were less often approved. This might be an indication that there is less externalized stigma in this Swedish sample but on the other hand that internalized stigma is a bigger problem. Maybe more efforts should be given to working with the self perception of our patients. This is also more within reach for the psychiatric service than trying to change the public perceptions. It is however hopeful that quite many approved items indicating stigma resistance.

\section{References}

[1] Ineland, L., Jacobsson, J., Renberg, E.S. and Sjölander, P. (2008) Attitudes towards Mental Disorders and Psychiatric Treatment-Changes over Time in a Swedish Population. Nordic Journal of Psychiatry, 62, 192-197. https://doi.org/10.1080/08039480801962855

[2] Hansson, L. (2012)Psykisk ohälsa-attityder, kunskap, beteende. En jämförande befolkningsstudie 2009-2012. Handisam/Hjärnkoll. 
[3] Hansson, L., Stjernswärd, S. and Svensson, B. (2014) Perceived and Anticipated Discrimination in People with Mental Illness-An Interview Study. Nordic Journal of Psychiatry, 68, 100-106. https://doi.org/10.3109/08039488.2013.775339

[4] Mirnezami, H., Jacobsson, L. and Edin-Liljegren, A. (2016) Changes in Attitudes towards Mental Disorders and Psychiatric Treatment 1976-2014 in a Swedish Population. Nordic Journal of Psychiatry, 70, 38-44. https://doi.org/10.3109/08039488.2015.1046916

[5] Ritscher, J.B., Otilingam, P.G. and Grajales, M. (2003) Internalized Stigma of Mental Illness. Psychometric Properties of a New Measure. Psychiatric Research, 121, 31-49. https://doi.org/10.1016/j.psychres.2003.08.008

[6] Boyd, J.E., Adler, E.P., Otlinger, P.G. and Peters, T. (2013) Internalized Stigma of Mental Illness (ISMI) Scale: A Multinational Review. Comprehensive Psychiatry, 55, 221-231. https://doi.org/10.1016/j.comppsych.2013.06.005

[7] Lysaker, P.H., Davis, L.W., Warman, D.M., Strasburger, A. and Beattle, N. (2007) Stigma, Social Function and Symptoms in Schizophrenia and Schizoaffective Disorder. Associations across 6 Months. Psychiatric Research, 149, 89-95.

https://doi.org/10.1016/j.psychres.2006.03.007

[8] Brohan, E., Gauci, D., Sartorius, N. and Thornicroft, G. (2011) Self-Stigma, Empowerment and Perceived Discrimination among People with Bipolar Disorder or Depression in 13 European Countries. Journal of Affective Disorders, 129, 56-63. https://doi.org/10.1016/j.jad.2010.09.001

[9] Brohan, E., Elgie, R., Sartoris, N. and Thornicroft, G. (2010) Self-Stigma, Empowerment and Perceived Discrimination among People with Schizophrenia in 14 European Countries. Schizophrenia Research, 122, 232-238. https://doi.org/10.1016/j.schres.2010.02.1065

[10] Ghanean, H., Nojomi, M. and Jacobsson, L. (2011) Internalized Stigma of Mental Illness in Tehran, Iran. Stigma, Research and Action, 1, 11-17. https://doi.org/10.5463/sra.v1i1.10

[11] Sartorius, N. (2012) Fighting Stigma of Mental Illness in Midsize European Countries. Social Psychiatry Psychiatric Epidemiology, 47, 1-38. https://doi.org/10.1007/s00127-012-0491-z

[12] Ritsch, N., Angermeyer, M.C. and Corrigan, P.W. (2005) Mental Illness Stigma: Concepts, Consequences and Initiatives to Reduce Stigma. European Psychiatry, 20, 529-539. https://doi.org/10.1016/j.eurpsy.2005.04.004

[13] Lucksted, A., Drapaiski, A., Calmes, C., Forbes, C., DeForge, B. and Boyd, J. (2011) Ending Self Stigma. Pilot Evaluation of a New Intervention to Reduce Internalized Stigma among People with Mental Illness. Psychiatric Rehabilitation Journal, 35, 51-54. https://doi.org/10.2975/35.1.2011.51.54

[14] Luuma, J.B., Kohlenberg, B.S., Hayes, S.C., Bunting, K. and Rye, A.K. (2008) Reducing Self-Stigma in Substance Abuse through Acceptance and Commitment Therapy; Model, Manual Development and Pilot Outcome. Addiction Research Theory, 16 149-165. https://doi.org/10.1080/16066350701850295 
Submit or recommend next manuscript to SCIRP and we will provide best service for you:

Accepting pre-submission inquiries through Email, Facebook, LinkedIn, Twitter, etc. A wide selection of journals (inclusive of 9 subjects, more than 200 journals)

Providing 24-hour high-quality service

User-friendly online submission system

Fair and swift peer-review system

Efficient typesetting and proofreading procedure

Display of the result of downloads and visits, as well as the number of cited articles Maximum dissemination of your research work

Submit your manuscript at: http://papersubmission.scirp.org/

Or contact ojpsych@scirp.org 